at the M.Sc. level, would be a useful measure towards the growth of participation by African students in the research programmes of physics departments. Secondly, the help of the Department of Scientific and Industrial Research and of other research-sponsoring organizations should be sought in the recruitment of research students from overseas.

In the absence of research students, much of the experi. mental work in a project has to be done by the lecturers, or by the small number of full-time research fellows. Progress is further retarded by the shortage of technicians. The supply of assistance at this level depends on the provision of secondary education (up to Ordinary-level) in mathematics and physics and also on the development of full-time or part-time technical education to the level of the Ordinary National Certificate or the City and Guilds final examination in appropriate subjects.

Educational facilities of this kind are essential to the development of a healthy industrial economy and are, therefore, of great importance in many African countries. Their provision will be a slow process, and physics depart. ments will have to rely on expatriate technicians-who can do valuable service in the training of indigenous staff.

Physics departments in Africa are isolated in the geographical sense, but they also face the danger of intellectual isolation. Many active areas of modern physics are closed to them, through lack of funds for equipment and staff. Contacts with other physicists are also very limited. Chemists and biologists can be found in most countries, going about their normal work in industry, agriculture or
Government service. Physicists are needed mainly in industrialized communities; consequently teachers in African universities can seldom sharpen their wits by contact with practising physicists in the outside world. African universities in general make reasonable provision for overseas leave; the Conference emphasized the value of attendance at scientific conferences and of frequent discussion with visiting research workers.

Despite many obstacles and discouragements, a lively spirit of enquiry is evident in many physics departments. Good use is being made of the excellent local opportunities for research in geophysics (including seismic studies and palæomagnetism), meteorology, cosmic radiation and ionospheric investigation. The cost of this research is largely defrayed by European or American sources or by international organizations.

Physics departments in Africa face some of the difficulties which were known in English provincial universities forty years ago. Student numbers are small (one African university has 186 first-year students in history, but only 15 in physics), because physics is not yet seen to have any immediate relevance to the needs of the community. The teaching load is nevertheless heavy. Funds for equipment are meagre and research is a constant struggle. British physics advanced rapidly as a consequence of the Second World War; the political upheaval which is now transforming the African scene must, for its full consummation, be accompanied by an upsurge of science and technology. Physicists now working in African countries are fully alive to their responsibilities at this exciting time.

J. M. A. LENIHAN

\title{
FREE RADICALS
}

T HE sixth International Symposium on Free Radicals was held in the Department of Physical Chemistry in the University of Cambridge during July 2-5. The meeting had an extensive scientific programme; but pre-printing of the papers made it possible to avoid parallel sessions. The delegates were accommodated in Trinity Hall, Sidney Sussex and Downing Colleges, and the social functions, which included a reception in the Guildhall and a guest night dinner held in St. John's and Downing Colleges, provided plenty of opportunity for discussions. The three hundred delegates included Dr. W. A. Noyes, jun. (president of the International Union of Pure and Applied Chemistry), Academician V. N. Kondratiev, Prof. S. Claesson, Prof. P. A. Giguère, Dr. G. Herzberg, Academician W. Kemula, Dr. Bernard Lewis, Dr. F. O. Rice and Prof. G. Semerano.

The inaugural lecture was given by Prof. R. G. W. Norrish, who discussed the many ways in which kinetic spectroscopy and flash photolysis have contributed to the understanding of the properties of free radicals.

As with previous symposia, the emphasis of the plenary lectures and contributed papers was primarily on free radicals in the liquid and solid states, although $H$. Schüler and G. Arnold (Göttingen) discussed the dissociation of cyclohexane and $n$-butane into different radicals and diradicals by slow electrons in the positive column of a glow discharge. Electron bombardment in the gas phase was also used by R. Marx, S. Leach and M. Horani (Orsay, Paris) to produce free radicals from water. The radicals which could be condensed from an electric discharge through water vapour were also discussed by $\mathrm{P}$. A. Giguère (Laval, Quebec). The closely related problem of using electron spin resonance to identify the radicals produced in the radiolysis of ice and hydrogen peroxidewater systems at low temperatures was discussed in a plenary lecture by R. Livingston (Oak Ridge, Tennessee) and in papers by D. Schulte-Frohlinde and K. Eiben (Karlsruhe), I. Safarik, B. C. Green and J. W. T. Spinks (Saskatoon) and S. J. Wyard and R. C. Smith (Guy's
Hospital, London). The existence of hydrogen superoxide $\left(\mathrm{H}_{2} \mathrm{O}_{4}\right)$ is not unequivocally established in these systems, but there is clear evidence for the trapping of $\mathrm{OH}$ and $\mathrm{HO}_{2}$. The nature of the active species in the radiolysis of aqueous solutions was also discussed in a plenary lecture by J. Weiss (King's College, Newcastle upon Tyne).

Several papers were concerned with the identification and study of the electron spin resonance spectra of trapped radicals produced by irradiation of both organic and inorganic solids. It was significant that a high proportion of the work reported was carried out on single crystals. These papers were preceded by a plenary lecture on the interpretation of hyperfine coupling by $\mathrm{D}$. $\mathrm{H}$. Whiffen (National Physical Laboratory, Teddington), and the parent compounds studied included persulphates by P. W. Atkins, J. A. Brivati, A. Horsfield, M. C. R. Symons and P. A. Trevalion (Leicester); nitrates by J. Cunningham (Chicago) and R. M. Golding and M. Henchman (Cambridge); fluorinated organic compounds by J. K. Brown and D. S. Stiles (Birmingham); succinimide by N. M. Atherton (Sheffield); olefines and alkyl halides by P. B. Ayscough and H. E. Evans (Leeds); organic acids by R. J. Cook, J. R. Rowlands and D. H. Whiffen (National Physical Laboratory, Teddington); and acetylene by E. L. Cochran, V. A. Bowers and F. J. Adrian (Applied Physics Laboratory, Johns Hopkins).

Three contributions described the use of electron spin resonance to examine reactions of radicals produced by irradiating both hydrocarbon polymers $(\mathrm{H}$. Fischer, K. H. Hellwege and P. Neudörfl (Darmstadt) and A. Charlesby, C. Graves, P. G. Garratt and P. M. Kopp (Royal Military College of Science, Shrivenham)) and polymethylsiloxane (H. Ormerod (Royal Military College of Science, Shrivenham)). Electron spin resonance was one of the many techniques mentioned by C. H. Bamford (Liverpool) in his plenary lecture on radical polymerization in the solid-state. The unusual reactivity and exceptional surface area of fluffs obtained by freeze- 
drying polymer solutions were reported by R. B. Ingalls (North American Aviation) and L. A. Wall (National Bureau of Standards, Washington). Surface properties were also considered by V. B. Kazanskii and G. B. Pariiskii (Moscow), who were able to obtain electron spin resonance spectra of free radicals adsorbed on surfaces of insulators but not of semiconductors.

The electron spin resonance spectra of organic diradicals such as substituted methylenes were reported by W. A. Yager, K. W. Murray, G. Smolinsky, A. M. Trozzolo and E. Wasserman (Bell Telephone Laboratories).

Chemical reactions studied in the solid-state using electron spin resonance spectroscopy included the benzene photosensitized decomposition of hydrocarbons (N. V. Fock, B. N. Shelimov and V. V. Veovodskii (Moscow)), the reaction of ethylene or oxygen using an ingenious rotating cryostat (J. E. Bennett and A. Thomas (Shell, Thornton)), and the photolysis of methyl iodide at $\lambda=2537 \AA$, where the methyl radicals rapidly extract hydrogen from the methylcyclohexane cage (J. M. Flournoy, H. S. Judeikis (Aerojet, California)).

Chemical analysis was used by R. H. Duffett and G. J. Minkoff (British Petroleum, Sunbury) to examine the reaction of hydrogen and deuterium atoms with solid olefines. Fluorescence spectra of benzyl radicals in cyclohexane glasses were studied by L. Grajcar and S. Leach (Orsay, Paris) to obtain information about the structure of the solid-state. For their studies oxygen in liquid and solid argon, A. M. Bass and H. P. Broida (National Bureau of Standards, Washington) used ultra-violet spectroscopy. The formation and decomposition of purple sulphur at low temperatures was illustrated with a colour film by F. O. Rice (Notre Dame, Indiana).

It is more difficult to maintain significant concentrations of reactive species in the liquid state than in the solid phase. Three of the papers, however, reported electron spin resonance investigations of short-lived radicals under liquid conditions. The use of a fast-flow system in which the reactants were mixed close to the sampling cell was reported by P. L. Kolker, T. J. Stone and W. A. Waters (Oxford), who produced aromatic radicals by oxidation of phenols, and by W. T. Dixon and R. O. C. Norman (Oxford), who formed various aliphatic radicals using titanous salt-peroxide systems. L. H. Piette (Varian, California) showed that both rapid response and good sensitivity would be obtained with an electron spin resonance spectrometer on a statistical basis. Electron spin resonance studies of radicals produced by the photolysis of electron-donor-acceptor system were reported by C. Lagercrantz (Göteborg) and the spectra of terphenyl anions by K. H. Hausser, L. Mongini and R. van Steenwinkel (Euratom, Ispra). The production and properties of ketyl radicals formed by polarographic reduction were described by Z. R. Grabowski and M. K. Kalinowski (Warsaw).

The importance of diffusion of radicals in solution was discussed in papers by J. E. Guillet and J. C. Gilmer (Tennessee Eastman) and A. D. Osborne and G. Porter (Sheffield) respectivoly. The former showed that solvent cages are important in the decomposition of diacyl peroxides and that the activation energies for radical escape from a cage and for diffusion are identical. The latter workers showed, by studying the decay of active species in solvents of different viscosity, that the Debye equation is valid when the reacting species do not differ greatly in size from the solvent molecules.

This stimulating meeting was assisted by the Royal Society, by many British industrial firms, and by the provision of transport for many North American Delegates by the United States Air Force. It is planned to hold the seventh Symposium in 1965 in Italy, probably in Venice.

B. A. Thrush

\section{INSPECTION OF ALKALI AND CEMENT WORKS}

\begin{abstract}
$\mathrm{T}$ HE ninety-ninth annual report on alkali, etc., works in England and Wales covering the year 1962 by the Chief Inspector * notes the extension by the responsibilities of the inspectorate by the Alkali, etc., Works Order, 1961, to cover control of emissions from calcination of black liquors from paper manufacture and from operations involving uranium, beryllium, selenium and their compounds. At the end of $1962,2,077$ works were registered under the Act, involving the operation of 3,247 separate processes, and 10,768 visits and inspections were made during the year, including 140 special visits by the Chief and Deputy Chief Inspectors. During the inspections, 4,331 quantitative analyses were made of gases evolved from processes, compared with 6,992 in 1961, but the latter total included 3,065 tests taken during a special investigation into emissions from the salt glazing of earthenware.

In addition, 647 special samples were taken and submitted for analysis to the Government Chemist. Specific complaints investigated during the year, largely at the request of local authorities, concemed 297 works, compared with 283 in 1961, 292 in 1960 and 354 in 1959, and of these 297 works 233 were registered under the Act, and the complaints were most numerous against gas and coke works (47), ceramic works (41), electricity works (33), iron and steel works (27), aluminium works (14) and cement works (13). The degree of justification for complaint varied, and once again was most bitter against some of the smaller works. There was also some general
\end{abstract}

* Ministry of Housing and Local Government; Scottish Development Department. Alkali, etc., Works Regulation Act, 1906, and Alkali, etc. Works Orders 1928-1961. Alkali, etc., Works Regulation (Scotland) Acts, 1906,1951 , and Alkali, etc., Works (Scotland) Orders, 1952 and 1958). Ninety-ninth Annual Report on Alkali, etc., Works by the Chief Inspectors, 1962. Pp. 75. (London: H.M.S.O., 1963.) 5s. net. complaint against overall emission in particular areas rather than against any specified works, and of the 16 examples include the blue-brick making area of Staffordshire and The Thames and Medway cement-making areas. Listed infractions, numbering 10 , were again confined to the pre -1958 processes and remedies were applied on formal notification by the inspector without institution of proceedings. The root cause of the trouble in the Thames cementmaking area was the approaching exhaustion of available Eocene clay supplies in North Kent and the consequent use of ever-increasing proportions of estuarine clay from the Cliffe marshes, and the resulting increased dust burden in the kiln gases has in turn led to overloading and erratic operation, or even failure, of electrical precipitates. Planning consent was sought to win sufficient Eocene clay from Essex to replace all the Cliffe clay in use and at the end of the year only one of the four works on the south bank of the Thames was on Cliffe clay. The report includes an interesting historical review of the evaporation of lime in open pans, a process for common salt now practically out of use and there is also a brief discussion of the problem of emissions from the Trophas steel con. verter. Although the Inspectorate is still much preoccupied with grit, etc., emissions from the intermediate-sized coal-fired power stations, considerable progress can be recorded in modernization and replacement of grit and dust collection plant, and there are reasonable grounds to believe that such emissions will be reduced to a satisfactory level, but concern is still expressed over the minimization of emissions of acid-soot from oil-fired power stations.

The annual report for 1962 of the Chief Inspector for Scotland, published under the same cover, records a decrease in the number of registered premises from 297 